\title{
Por uma história comparada das estatísticas nas Américas
}

\section{For a comparative history of statistics in the Americas}

Angelo Alves Carrara

Estatísticas nas Américas: por uma agenda de estudos históricos comparados. Nelson de Castro Senra $\mathcal{E}$ Alexandre de Paiva Rio Camargo (orgs.). Rio de Janeiro: IBGE, Centro de Documentação e Disseminação de Informações, 2010, 428 p. (acompanha um CD-ROM em bolso).

Estatísticas nas Américas é livro que já pelo subtítulo vale uma boa acolhida pelos leitores. Uma agenda de estudos históricos sob uma perspectiva comparada é, sem dúvida alguma, algo de que necessitamos intensamente. Por isso, para além do próprio conteúdo da obra, a explicitação desse propósito já na capa

Angelo Carrara é professor de História Contemporânea e História de Minas Gerais da Universidade Federal de Juiz de Fora, Minas Gerais, Brasil (angelo.carrara@ufjf.edu.br).

Resenha recebida em 2 de junho de 2010 e aprovada para publicação em 9 de setembro de 2010.

Est. Hist., Rio de Faneiro, vol. 23, no 46, p. 377-384, julho-dezembro de 2010. 
atua como chamamento à atenção dos pesquisadores. Trata-se de um conjunto de textos sobre a pesquisa histórica das estatísticas, resultantes, uma parte, de uma das sessões da Latin American Studies Association - LASA 2009, no Rio de Janeiro, e outra parte, de sessão celebrada no próprio IBGE em torno do tema. Como assinalam seus organizadores na introdução, o debate então suscitado nas sessões mencionadas "realçou o estado atual das pesquisas históricas da atividade estatística, sejam as feitas nas instituições estatísticas, sejam as feitas em ambiente acadêmico".

Outra virtude, que nunca é demais encarecer, é que todos os autores tiveram acesso prévio às contribuições de cada um, o que aumenta a coerência interna da obra. Os resultados alcançados permitem extrair algumas conclusões importantes. Em primeiro lugar, no âmbito das diferenças entre os países. No Brasil, por exemplo, as pesquisas sobre as estatísticas históricas encontraram no IBGE a instituição privilegiada, sendo muito menos importante a contribuição acadêmica. $\mathrm{O}$ inverso ocorre nos outros países: é da academia que provêm as maiores contribuições. Nesse sentido, concordo plenamente com os organizadores quando afirmam ser o "IBGE o depositário da memória estatística brasileira, desde os tempos do Império, de cuja tradição é herdeiro legítimo, e não ter, ainda, conseguido publicizá-la amplamente".

Para todos quantos trabalhamos com dados seriais e quantitativos, as estatísticas assumem uma importância capital. $O$ fato de nos últimos anos virem se tornando um objeto de estudo reforça a ideia do seu papel para os diversos campos do saber. A sofisticação dos procedimentos de coleta de dados e a submissão dos dados coletados ao escrutínio de metodologias variadas são apenas alguns elementos que permitem aferir suas possibilidades e limites. Ao lado da coerência interna das contribuições, o volume e a diversidade de temas da coletânea requerem que nesta resenha se faça uma síntese do conteúdo de cada capítulo, na qual buscar-se-á desviar-se minimamente dos resumos apresentados pelos próprios autores.

Os capítulos são distribuídos por cinco partes. Abre o conjunto de seis capítulos da primeira parte o texto de Jean-Pierre Beaud e Jean-Guy Prévost, "L'histoire de la statistique canadienne dans une perspective internationale et panaméricaine", no qual os autores analisam cerca de dois séculos de práticas estatísticas no Canadá, enfatizando particularmente os paralelos possíveis com outras experiências nas Américas. Os autores apoiam-se no conceito de "regime estatístico", entendido como o complexo formado, num dado período, pelas estruturas, normas e práticas estatísticas. A partir dele, os autores distinguem quatro regimes: o primeiro, denominado de pré e proto-estatística, caracteriza a época anterior aos meados do século XIX; o segundo, marcado pelo fenômeno da nacionalização estatística, abrange o período de meados do século XIX ao primeiro terço do século 
$\mathrm{XX}$; o terceiro, estruturado em torno da ideia de macro-management estatística, situa-se no coração do século XX; e, por fim, o quarto, a partir dos anos 1980, no contexto de globalização neoliberal.

Os três textos seguintes têm por objeto a prática estatística na Argentina. O primeiro, de Hernán Otero, intitulado "La historia de la estadística en las universidades y en los institutos nacionales de estadística; el caso argentino", propõe uma periodização da historiografia estatística argentina a partir da diferenciação entre as produções acadêmicas e as derivadas dos órgãos oficiais de estatística, as quais tiveram dinâmicas próprias, mas igualmente convergências. "La elite estadística y el Estado argentino (1869-1947)" é o título do capítulo assinado por Hernán González Bollo, que tem por objeto a formação, consolidação e expansão da elite estatística na administração pública ao longo do processo de realização dos quatro primeiros censos argentinos. González Bollo mostra como essa elite ampliou sua liderança burocrática no processo de expansão do Estado, e que, ao desenvolver sofisticados planos de modernização nacional, tornaram-se verdadeiros tecnocratas antes do tempo. Em "Las estadísticas argentinas como objeto de estudio. Ejercicio de formalización de una experiencia de investigación histórica", Claudia Daniel discute os modos pelos quais a sociedade argentina foi representada por meio das cifras durante o período do Estado oligárquico. Nesse sentido, a autora apresenta abordagens historiográficas que vinculam a produção da estatística enquanto saber especializado ao exercício de formas de dominação, que vão do uso político dos censos às tomadas de decisão do Estado, e enfoca o problema do tratamento das fontes e as dificuldades que os pesquisadores enfrentam no seu uso.

Os dois capítulos seguintes têm a experiência produzida no âmbito do IBGE como objeto. Em "Informação estatística como forma de saber e fonte de poder, moldura teórica do 'Projeto História: 1822-2002' no IBGE”, Nelson de Castro Senra trata as estatísticas como como forma de saber e como fonte de poder. $\mathrm{O}$ autor parte do lento processo de construção das estatísticas como objeto de estudo e caminha na direção de um movimento de crescente questionamento sobre o estatuto científico das pesquisas quantitativas, que culmina nos anos $1970 \mathrm{e}$ 1980, considerados como inflexão epistemológica. O capítulo enfatiza duas grandes frentes de investigação, renovadas pela incorporação analítica das estatísticas: a construção dos Estados nacionais através de sua administração pública e as representações coletivas como espaço de disputas sociais. Encerra a primeira parte o capítulo assinado por Alexandre de Paiva Rio Camargo intitulado "Historiografia de um objeto multifacetado", em que apresenta um panorama sobre o lugar ocupado pela estatística no discurso historiográfico. Um ponto alto do texto é a reflexão do autor sobre as possibilidades e limitações da pesquisa histórica realizada em um instituto de estatística sólido e eficiente, como o IBGE, 
valendo-se para isso de sua experiência como pesquisador na coleção História das Estatísticas Brasileiras. Voltarei a este tema ao final.

A segunda parte, intitulada "Narrativas sócio-históricas: Estado e instituições", compõe-se de cinco textos cujo objeto é a relação das estatísticas com os Estados e instituições sociais, tais como a universidade, comunidades profissionais, associações de classe e a imprensa. Em "Las estadísticas oficiales en la prensa escrita porteña (Argentina, 1890-1930)", Hernán González Bollo e Claudia Daniel interrogam-se sobre o espaço intangível entre a produção da elite estatística e a divulgação dos números oficiais nas páginas da imprensa escrita. Mais propriamente, analisam as reações públicas que, entre 1890 e 1930, foram recolhidas das tarefas rotineiras da burocracia estatística argentina e que se manifestaram em artigos de jornais, resenhas e informes oficiais e editoriais. González Bollo e Daniel mostram como a fiscalização da imprensa contribuiu decisivamente para consagrar a linguagem estatística (com seus traços de impessoalidade, distanciamento e neutralidade) no seio da opinião pública da Argentina.

Em seguida, Alexandre de Paiva Rio Camargo apresenta um rápido relatório de uma sessão ocorrida no seminário internacional que originou o livro, e que contou com a participação do cientista político Wanderley Guilherme dos Santos, do historiador Tarcísio Rodrigues Botelho e do demógrafo Luiz Antonio Pinto de Oliveira.

O capítulo seguinte, "Síntese da 'História das Estatísticas Brasileiras: 1822-2002' feita no IBGE, com sugestões de pesquisa”, discute os critérios que resultaram num esforço de periodização utilizada nessa coleção. Seu autor, Nelson de Senra, destaca quatro grandes períodos: o das "estatísticas desejadas" (1822-1889), o das "estatísticas legalizadas" (1889-1936), o das "estatísticas organizadas" (1936-1972) e o das "estatísticas formalizadas" (1972-2002). Senra destaca ainda os personagens e temas mais fecundos aos estudos históricos correspondentes a cada período, e apresenta outras obras de história produzidas no âmbito do IBGE.

Em "Classificações raciais e formação do campo estatístico no Brasil (1872-1940)", Alexandre de Paiva Rio Camargo investiga os sentidos assumidos pela classificação racial nos primeiros censos brasileiros, tanto em função de sua inclusão (em 1872, 1890 e 1940) quanto de sua omissão (em 1920). O autor discute o papel do argumento racial e das exigências técnicas na tomada de posição dos estatísticos em três momentos distintos: o Império (1822-1889), a Primeira República (1889-1930) e a Era Vargas (1930-1945). Devo ressaltar que a ênfase deste capítulo é a análise da progressiva liberação da ideologia estatística dos mecanismos da propaganda política em torno da cor e, nesse sentido, assume especial importância a análise dos significados da presença ou ausência da classificação racial nos censos brasileiros de 1872, 1890, 1920 e 1940. Segundo Camargo, os três períodos 
destacados configuram três modos diferentes de encarar tanto as estatísticas quanto o Estado e a sociedade por meio das estatísticas no Brasil. O autor destaca a especificidade desta relação no sistema estatístico brasileiro, e conclui que a criação do IBGE, bem como a realização do censo de 1940 representaram uma virada na organização do campo, por acentuar o conflito estrutural entre a função prioritariamente política até então reservada às estatísticas e a consagração da competência técnica de seus produtores.

No último capítulo da segunda parte, intitulado "Censos nacionais brasileiros: da estatística à demografia", Tarcísio Rodrigues Botelho investiga a evolução dos censos vista a partir da consolidação da demografia como disciplina científica. Seu argumento é que os censos demográficos anteriores a 1940 foram apenas versões um pouco mais sofisticadas dos antigos levantamentos populacionais, estando interessados sobretudo em fornecer dados sobre o poderio do Estado nacional, e de que apenas com a consolidação da demografia como disciplina acadêmica é que começaram a ser introduzidas inovações que foram conferindo aos censos brasileiros não apenas instrumentos para medir a nação (e o Estado), mas também condições para responder a questões colocadas pelos estudos populacionais. Botelho considera que isto teria ocorrido no Brasil a partir do censo de 1940, consolidando-se nos censos seguintes. Aqui já aparecem as concordâncias com as periodizações anteriormente vistas. $\mathrm{O}$ autor analisa, ainda, os processos técnicos e a cobertura temática dos censos, inclusive os projetos daqueles que não se realizaram, como o de 1852, para destacar uma transformação de paradigma, localizada a partir do censo de 1940: de instrumento de mensuração do Estado nacional, sua força e seus recursos. A partir de então, os censos brasileiros tornaram-se instrumentos de investigação social, orientados pela pauta das pesquisas demográficas.

Na terceira parte - "Narrativas sócio-históricas: ciência e técnica" -, dois capítulos são integralmente dedicados à experiência mexicana. O primeiro, "Los censos en el siglo XVIII. El caso del censo novohispano de 1790: discusiones sobre inferencia estadística", assinado por Leticia Mayer, parte de uma formulação básica: os censos podem ser considerados tanto alternativas políticas, como formas de conhecimento em dois níveis - o do saber científico da estatística e o da compreensão da realidade da população num dado espaço. A partir deste duplo significado, a autora se debruça sobre uma polêmica entre o vicerrei da Nova Espanha, o segundo conde de Revillagigedo, e o padre José Antonio de Alzate y Ramírez. O texto de Mayer revela a alternativa metodológica apresentada pelo padre Alzate, por meio da qual os números oficiais eram desmentidos, tornando a Cidade do México maior que Madri. Para além do debate metodológico, este texto deve interessar a todos quantos se interessam pelo debate sobre as relações colônia-metrópole de fins do século XVIII. 
O segundo capítulo da terceira parte, de Laura Cházaro, leva o título "La vida y su valor a discusión: juicios médicos y cálculos de probabilidades entre médicos mexicanos del siglo XIX", e começa com uma indagação interessantíssima: "¿Cómo fue que la vida se convirtió en materia de aseguramiento, por lo tanto objeto de medición estadística y probable, sujeto de inversión, traspaso y venta?" A partir desta questão, a autora explora as diferentes noções de probabilidade, risco e vida em discussão entre os fins do século XIX e princípios do século XX, do ponto de vista dos médicos, os quais, nessa época aceitavam que sua prática implicava probabilidades e julgamentos que, ainda que calcados em perícia, podiam estar errados. Procurando solidificar estas fraquezas do conhecimento médico, os higienistas optaram por sistematizar estatísticas médicas, mas sem o recurso ao cálculo das probabilidades, geralmente identificado com as apostas e jogos de azar. Logo os médicos se integraram às companhias de seguros, abrindo-se às tabelas de mortalidade e cálculos de probabilidade.

A quarta parte do livro, intitulada "Como seguir adiante?", é dedicada principalmente à proposição de caminhos para uma sistematização dos estudos históricos comparados, em escala regional. É notável o mérito desta sessão, pois ultrapassa o balanço historiográfico e parte para algo verdadeiramente imprescindível em reuniões científicas como as que originou o presente livro: apontar os passos futuros. No seu "Sociologia, sínteses teóricas e a conformação de uma agenda de pesquisas sobre estatísticas públicas no Brasil", Renato Sérgio de Lima reflete sobre a necessidade de institucionalização de uma agenda e de um programa de pesquisas sobre produção e uso de estatísticas públicas no Brasil e nos demais países da América Latina, que tenha por referência uma perspectiva histórica e comparada. Após uma rápida contextualização de como a sociologia aborda a perspectiva histórica e de que modo esse movimento tem ligação com o processo de desenvolvimento da própria disciplina, a atenção do autor se volta para a discussão da necessidade de se formular sínteses teóricas capazes de superar a falsa antinomia entre o quantitativo e o qualitativo no nível epistemológico.

No capítulo seguinte, "O futuro da pesquisa histórica no IBGE (e no Brasil)", Nelson de Castro Senra analisa a pesquisa histórica realizada no IBGE, e pensa seu futuro próximo. Descreve a recepção do Projeto História das Estatísticas Brasileiras na comunidade de historiadores, bem assim os eventos e iniciativas por ele estimulados. A seguir, passa em revista o grau de institucionalidade alcançado pela pesquisa histórica no IBGE, apontando para suas tendências futuras. Por fim, chama a atenção para a necessidade de o IBGE, ao lado de sua agenda particular de pesquisa histórica, conquistar o envolvimento da comunidade acadêmica. As ponderações de Senra são indispensáveis, mas o movimento inverso, da parte dos historiadores, também deve ser enfatizado.

Em "As estatísticas brasileiras e a demografia histórica", Tarcísio Botelho assinala que, não obstante as contribuições inovadoras que trouxe para a 
abordagem do passado, a demografia histórica está pouco desenvolvida entre os historiadores brasileiros. Tarcísio se dedica então a apresentar a disciplina, bem como suas perspectivas específicas no âmbito da produção historiográfica brasileira. De início, trata da constituição da demografia propriamente dita e do surgimento da demografia histórica em geral para, em seguida, apontar suas possibilidades de estudo no Brasil, tanto em função da trajetória da disciplina na historiografia brasileira quanto em relação às fontes de dados disponíveis. No que respeita ao caráter propositivo dessa quarta parte, Tarcísio Botelho chama a atenção para a necessidade de tratamento dos acervos documentais, sobretudo os do interior do país, de preservação precária e distante do poder público, posição da qual comungo plenamente.

O capítulo "Reflexiones sobre algunos estudios en historia de las probabilidades y las estadísticas en México", de Letícia Mayer, contém uma série de reflexões sobre os principais problemas enfrentados no México para o desenvolvimento da história das probabilidades e das estatísticas. Segundo a autora, esta problemática compreende o interesse e o motivo das pesquisas, o contexto institucional, as abordagens do campo de estudo e as línhas de pesquisa. Leticia Mayer apresenta diversas estratégias que permitem abordar a estatística em sua especificidade constitutiva, reunindo os métodos das ciências mais duras e os problemas políticos e sociais implicados em toda tecnologia de controle.

Por fim, "Puntos de llegada que son puntos de partida. El estudio de las estadísticas en Latinoamérica y la proyección de un horizonte comparativo", por Claudia Daniel. De imediato reconheça-se a propriedade das palavras dos organizadores na introdução, a respeito deste capítulo, ao afirmar que não podem chamar de conclusão esta última contribuição: "seu título não deixa margens à dúvida: realiza um aguçado esforço de síntese, fornecendo os primeiros aportes para uma agenda de estudos históricos comparados". Repito aqui as palavras da autora, que tomarei adiante para discussão: "la tarea comparativa nos pone ante nuevos desafíos y uno, no poco importante, es el de traducir los códigos o vocabularios diferentes empleados por los investigadores de cada lugar. La articulación entre investigadores podría, sin embargo, contribuir a saldar otro de los desafíos que presenta para un investigador singular un trabajo comparativo: el de dominar con similar nivel de profundidad los casos que investiga."

Encerram a obra duas entrevistas reveladoras das trajetórias intelectuais de Jean-Pierre Beaud e Hernán Otero.

Como o leitor pode avaliar, estão plenamente justificadas as duas primeiras frases desta resenha. A presente obra pode ser inscrita numa antiga tradição cultivada desde os fins do século XIX no Brasil, que se fortaleceu nas décadas de 1930 a 1960 para perder um pouco do vigor desde então: a do diálogo entre a geo- 
grafia e a história. Poder-se-ia aqui lembrar que a primeira instituição que nesses dois campos do conhecimento desempenhava o papel de centro de investigação denominava-se Instituto Histórico e Geográfico Brasileiro (IHGB), mas os melhores frutos desse diálogo são bem posteriores à data de sua fundação.

A obra magistral de Philipp von Luetzelburg [1880-1948], Estudo botânico do Nordeste, em três volumes, publicada entre 1925 e 1926, foi o resultado da expedição que o autor fez entre 1911 e 1912 por $3.500 \mathrm{~km}$ de caminhos coloniais do Nordeste a ele informados por Capistrano de Abreu. Este diálogo, ainda pouco conhecido entre nós, parece ter frutificado anos mais tarde nas páginas da $R e$ vista Brasileira de Geografia, publicada a partir de 1939, e em cujas páginas podíamos encontrar estudos valiosos, por exemplo, de história demográfica ou econômica. É curioso que o ano de seu primeiro número coincidisse com o centenário da fundação de outra revista, que cumpriu papel semelhante um século antes, a do mencionado Instituto Histórico e Geográfico Brasileiro. De certa forma, o centenário do IHGB marca um refluxo para a historiografia no Brasil, em oposição ao extremo vigor experimentado pela Geografia.

Se a necessidade de diálogo interdisciplinar é algo absolutamente inescapável, o mesmo tem de ser dito com relação à adoção de uma perspectiva comparada. E nesse sentido, a presente obra oferece, mais do que um simples convite a quantos se interessem pela matéria, um desafio, pelo que retomo aqui a proposta de Claudia Daniel no capítulo final do livro. Antes de mais nada, temos de estabelecer uma nomenclatura comum que nos permita identificar com clareza o que se está comparando, o que só é possível, por seu turno, a partir do conhecimento abrangente das realidades históricas nacionais. Estatísticas nas Américas é o primeiro passo nesse sentido. 